\title{
Políticas PÚblicas de DESENVOLVIMENTO RURAL PARA A AGRICULTURA FAMILIAR: ANÁlises do PRONAF nO ESTAdo de SANTA CATARINA, BRASIL
}

\author{
PUBliC RURAL DEVELOPMENT POLICIES FOR FAMILY FARMING: \\ ANALYZES OF PRONAF In THE STATE OF SANTA CATARINA, BRAZIL
}

\author{
Alessandra Matte ${ }^{1}$ \\ http://orcid.org/0000-0002-0502-6643 \\ Juliano Luiz Fossá ${ }^{2}$ \\ http://orcid.org/0000-0002-9658-4850 \\ Lauro Francisco Mattei ${ }^{3}$ \\ http://orcid.org/0000-0002-1270-8052
}

Submissão: 11/05/2020 / Aceito: 23/06/2020.

\begin{abstract}
Resumo
A problemática deste artigo contempla o acesso à política pública do PRONAF no estado de Santa Catarina, tendo como objetivo analisar a distribuição dos contratos e recursos financeiros do Programa Nacional de Fortalecimento da Agricultura Familiar (PRONAF) no estado de Santa Catarina para o período compreendido entre 1996 e 2016. Foram elencados e analisados indicadores de distribuição no acesso às linhas de custeio e de investimento da política de crédito rural PRONAF, entre os quais o número de contratos, o volume de recursos, a finalidade e a distribuição por região. Os resultados apontam que o volume de recursos no período de 1996 a 2016 cresceu 5,5 vezes, o equivalente a 550\%. A maior parcela dos recursos do crédito é destinada ao custeio, o que não impediu o registro de significativos incrementos a partir de 2006 para a linha de crédito de investimento. É possível concluir que o PRONAF consiste em importante política pública de apoio ao segmento familiar rural do estado de Santa Catarina, visto o aumento no número de acessos e no montante repassado ao longo do período analisado.
\end{abstract}

Palavras-chave: Agricultores familiares; Crédito Rural; Santa Catarina.

\begin{abstract}
The purpose of this article is to analyze the distribution of contracts and financial resources of the National Program for Strengthening Family Farming (PRONAF) in the state of Santa Catarina for the period between 1996 and 2016. Distribution indicators for access to the PRONAF, including the number of contracts, the volume of resources, the purpose and the distribution by region. The results show that the volume of resources in the period from 1996 to 2016 grew 5.5 times, equivalent to $457.9 \%$. Most of the credit resources are used to finance costs, which has not prevented the recording of significant increases since 2006 for

\footnotetext{
${ }^{1}$ Zootecnista, Mestre e Doutora em Desenvolvimento Rural (UFRGS). Professora Adjunta na Universidade Tecnológica Federal do Paraná (UTFPR), Campus Santa Helena/PR.

${ }^{2}$ Economista, Mestre em Políticas Sociais e Dinâmicas Regionais (Unochapecó), Doutorando em Administração (UFSC).

${ }^{3}$ Agrônomo e Doutor em Economia. Professor Titular na Universidade Federal de Santa Catarina (UFSC).
} 
the investment credit line. It is possible to conclude that PRONAF consists of an important public policy to support the rural family segment in the state of Santa Catarina, given the increase in the number of accesses and the amount transferred over the period analyzed.

Keywords: Family farmers. Rural credit. Santa Catarina.

\section{INTRODUÇÃO}

A partir da institucionalização do Programa Nacional de Fortalecimento da Agricultura Familiar (PRONAF) em 1996, o segmento rural familiar passou a contar com uma política pública específica de apoio ao fortalecimento e desenvolvimento das atividades socioprodutivas por meio da disponibilidade de acesso ao crédito. Desde sua implantação, o programa passou a estar ao alcance de agricultores familiares de todas as regiões do país em termos de contratos assinados e volume de recursos concedidos.

O estado de Santa Catarina, situado na região Sul do país, é um importante produtor agrícola e pecuário, com relativa contribuição em âmbito nacional (FACHINELLO, SANTOS FILHO, 2010). Conforme dados do Censo Agropecuário de 2017, 78,1\% dos estabelecimentos rurais de Santa Catarina se enquadram como propriedades rurais familiares, de acordo com a Lei 11.326/2006, a qual estabelece as diretrizes para a formulação da Política Nacional da Agricultura Familiar e Empreendimentos Familiares Rurais e regulamenta o público-alvo que poderá acessar o crédito rural por meio do PRONAF.

A importância dessa política pública para as formas familiares de produção é reconhecida em distintos estudos que ilustram alguns resultados do acesso ao crédito tanto para produtores como para as comunidades em que estes estão inseridos -, assim como o desdobramento dessa política em adequações para públicos e práticas específicas (GRISA， SCHNEIDER， 2015; SPANEVELLO; MATTE; BOSCARDIN， 2016; BRAMBILLA; MICHELLON, 2019). Em análise a respeito da distribuição do Pronaf entre as regiões brasileiras para o período compreendido entre 1999 e 2014, Monteiro e Lemos (2019) demonstram crescimento no número de contratos e de valores transferidos, com desempenho positivo com relação à promoção do desenvolvimento rural, especialmente de agricultores familiares. Diante disso, este estudo propõe como objetivo analisar o acesso ao crédito PRONAF no estado de Santa Catarina, evidenciando sua evolução em termos de contratos e volume de recursos acessados no período de 1996 a 2016. O objetivo é alcançado por meio da apresentação e discussão dos dados referentes às linhas de crédito de 
custeio e de investimento, bem como a distribuição por região e municípios do estado. A escolha do período refere-se ao ano de início da política até o período em que tais dados estavam disponíveis quando da realização deste levantamento.

Os dados analisados foram acessados junto ao Banco Central do Brasil, consistindo dos dados financeiros deflacionados a partir do Índice Nacional de Preços ao Consumidor (INPC) para o ano de 2016. A realização desta pesquisa justifica-se a partir de três aspectos principais: i) a significativa presença da agricultura familiar no estado de Santa Catarina; ii) a expressiva participação do estado quanto ao acesso dos recursos em âmbito nacional; iii) interesse dos pesquisadores em fomentar estudos na temática da economia catarinense e da agricultura familiar.

Para tanto, este artigo está estruturado em quatro seções além desta introdução. $\mathrm{Na}$ primeira seção são tecidas breves considerações referentes à conceituação de agricultura familiar e política pública de crédito rural para agricultura familiar, o PRONAF. Na segunda seção são apresentados os aspectos metodológicos empregados nesta pesquisa. Em continuidade, na terceira seção são apresentadas as análises de distribuição do PRONAF em Santa Catarina por regiões, tanto no que se refere ao volume de recursos como ao número de contratos. Por fim são elaboradas considerações finais e proposições de estudos futuros a partir dos resultados aqui encontrados.

\section{Agricultura familiar e a Política Pública do Pronaf}

Os referenciais teóricos há muitos anos classificam e distinguem a agricultura brasileira na dualidade de agricultura patronal/empresarial e agricultura familiar, sendo esta o foco deste estudo. Mattei (2005) aponta que esses agricultores familiares também são designados como pequenos produtores, produtores familiares, produtores de baixa renda ou agricultores de subsistência ${ }^{4}$. Entretanto, parte-se do entendimento de que os conceitos se alteram com o passar dos anos, conforme apontado por Seyferth (2011, p. 397), que afirma que "as definições são ferramentas do pensamento e não verdades que duram para sempre".

Para Guanziroli (2000), uma das possibilidades para classificar a agricultura familiar é a partir das formas e organização social do seu processo produtivo, que essencialmente se caracterizam pelos seguintes aspectos: mão de obra familiar; maior parte

\footnotetext{
${ }^{4}$ Em estudo sobre a região oeste de Santa Catarina, Campos 1987 classifica esse segmento como "Colonos".
} 
da renda advinda do trabalho familiar na propriedade; produção diversificada; e estabelecimentos rurais familiares. Por isso, em muitas situações, a delimitação de tipos de agricultura serve ao propósito de oferecer programas e políticas específicas a determinada categoria. A este respeito, a construção de legislações perpassam classificações que assumem características gerais do segmento enquadrado.

Em 2006, a Lei 11.326 definiu que agricultor familiar é aquele que pratica suas atividades produtivas no meio rural e atende às seguintes condições: (a) não detenha, a qualquer título, área maior do que 04 (quatro) módulos fiscais; (b) utilize predominantemente mão de obra da própria família nas atividades econômicas do seu estabelecimento ou empreendimento; (c) tenha percentual mínimo da renda familiar originada de atividades econômicas do seu estabelecimento ou empreendimento, na forma definida pelo Poder Executivo; e (d) dirija seu estabelecimento ou empreendimento com sua família (BRASIL, 2006). O estabelecimento dessa definição teve como propósito distinguir esses produtores daqueles que possuem maior capital de giro e capital imobilizado, permitindo identificar os produtores rurais que merecem maior atenção e suporte do Estado (FAO/INCRA, 1994).

A esse respeito, o Programa Nacional de Fortalecimento da Agricultura Familiar (PRONAF) é constituído em 1996 com a finalidade de atender especificamente a categoria de agricultores familiares. Grisa, Wesz Junior e Buchweitz (2014) afirmam que a criação do PRONAF significou aos agricultores familiares a passagem de uma condição de produtores de ditos de menor importância para a condição de produtores de reconhecido valor no setor de produção de alimentos, devido ao estabelecimento de uma política pública exclusivamente destinada à agricultura familiar.

Estabelecido a partir do Decreto Presidencial N. 1.946/1996, principalmente por meio de ações e movimentos de diversos segmentos civis organizados, especialmente os vinculados às questões agrárias e sindicatos dos trabalhadores, o programa oferece crédito rural para pagamento a longo prazo e com juros subsidiados (MATTEI, 2015). A estrutura do programa, bem como seus objetivos e finalidades, foi desenhada a partir de estudos da FAO/INCRA e do Programa de Valorização da Pequena Produção Rural (PROVAPE), tendo como principal finalidade do programa a concessão de uma linha de crédito específica para agricultura familiar (BIANCHINI, 2015). 
A principal forma de financiamentos das atividades produtivas do meio rural familiar passa a ser o PRONAF, com taxas de juros abaixo do que tradicionalmente pratica o mercado financeiro tradicional, prazos maiores, subsídios, e, também, assegurando condições de pagamento adequadas à realidade da agricultura familiar (CARNEIRO, 1997).

Nesse sentido, Grisa e Schneider (2015, p. 29) reafirmam que "O PRONAF se constitui na principal política agrícola para agricultura familiar (tanto em número de beneficiários, capilaridade nacional e recursos aplicados) [...]”. Essa condição se evidenciou a partir do ano de 2003, quando o governo federal elegeu a agricultura familiar como prioridade na estratégia de desenvolvimento.

Esta priorização resultou em expressivo aumento no volume de recursos disponibilizados. No período entre 1996 a 2002, o valor financiado passou de R\$1,9 bilhões para R \$ 6,5 bilhões. Já no período de 2003 a 2010, os valores passaram de R\$ 6,7 bilhões para $\mathrm{R} \$ 17,9$ bilhões, e no ano de 2014 foi registrado o maior volume de crédito disponibilizado desde a implantação do PRONAF: R \$ 29,2 bilhões.

Os dados evidenciam a acentuada expansão do programa em termos de volume de crédito concedido. $\mathrm{O}$ número de contratos também se expandiu de forma mais intensa a partir de 2003, passando de pouco mais de 800 mil em 2002 para 1,5 milhões de contratos em 2010, conforme ilustrado no Gráfico 1. O maior número de contratos foi registrado em 2006, com 2,5 milhões de operações.

Gráfico 1 - Evolução do número de contratos efetivados via PRONAF no Brasil no período de 1996 a 2016

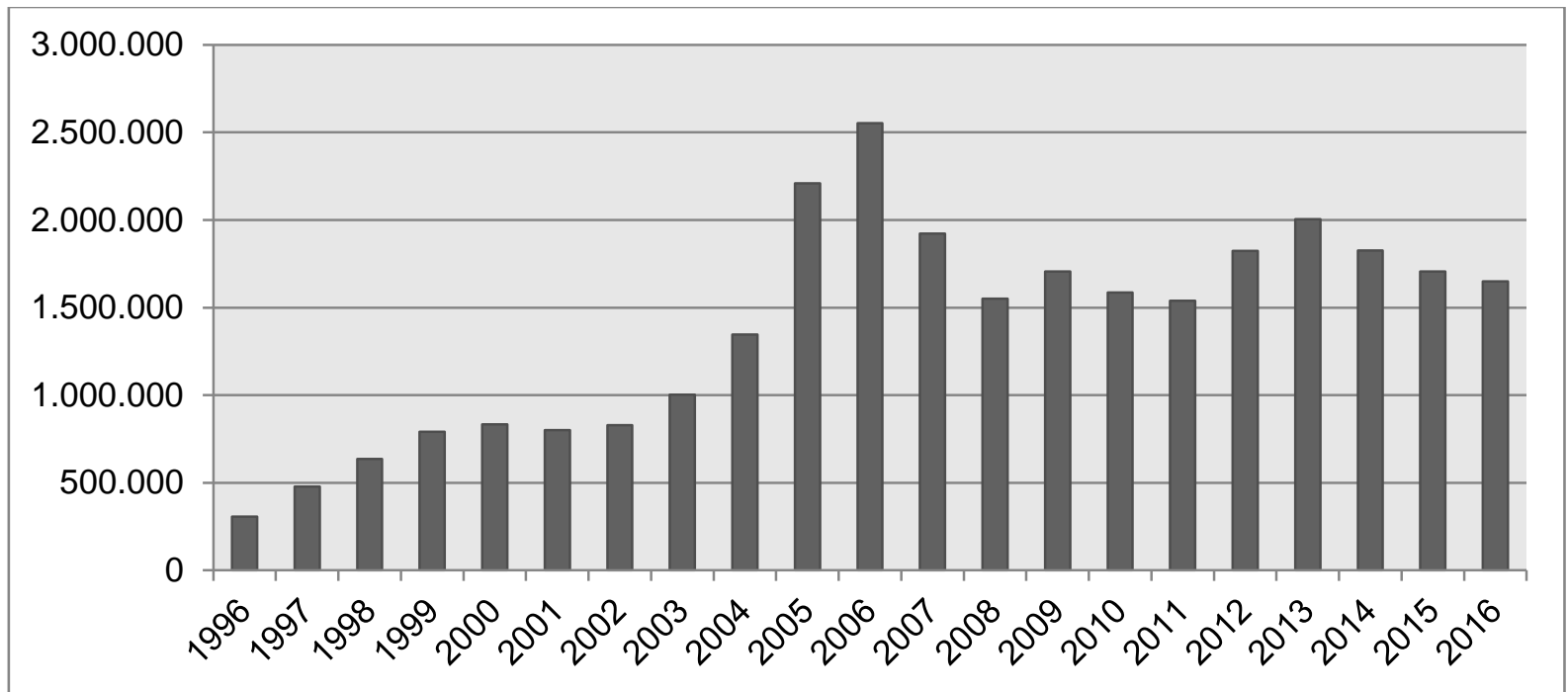

Fonte: Elaboração dos autores com base em dados do Banco Central do Brasil (2016). 
Para Mattei (2015, p. 13), esses avanços ocorreram porque “[...] houve um processo de inclusão de novos agricultores como beneficiários dessa política pública”, uma vez que, para o autor, houve o "[...] cumprimento das promessas do Governo Lula (2002), que a partir de 2003 elegeu o apoio à agricultura familiar como uma das prioridades de sua política de desenvolvimento rural do país".

Em complemento, Aquino e Schneider (2015) apontam que o PRONAF, com o passar dos anos, foi entendido, especialmente pelos seus gestores públicos, como política pública capaz de estabelecer uma estratégia em âmbito nacional de ampliação da diversidade social da agricultura familiar no meio rural.

Os recursos acessados pelos agricultores familiares e o número de contratos efetivados desde o início das operações do PRONAF tiveram incremento significativo, e consequentemente possibilitaram a expansão do programa em todas as regiões do país. Nesse sentido, Wanderley (2017, p. 69) é consistente ao afirmar que "Não resta dúvida que o PRONAF representou um salto significativo em relação às políticas anteriormente praticadas".

Entretanto, o PRONAF, na condição de política pública, ainda possui diversos desafios a serem superados, com destaque para uma ainda maior ampliação do programa, especialmente aos menos capitalizados, e o fortalecimento de suas linhas específicas de atuação, como por exemplo, o PRONAF Jovem e o PRONAF Mulher (SPANEVELLO; MATTE; BOSCARDIN, 2016). Partindo das considerações apresentadas nesta análise inicial, na próxima seção é apresentada os instrumentos de acesso aos dados e de sua análise, levando em conta as contribuições aqui ilustradas.

\section{MÉTODO DE PESQUISA}

A aproximação com a realidade leva a produzir conhecimentos a partir de experiências em diferentes espaços e contextos sócios-históricos. Em se tratando do conhecimento científico, este aperfeiçoa o uso da racionalidade ao propor uma forma sistemática, metódica e crítica de desvelar e explicar a realidade (KOCHE, 2013).

Nessa mesma perspectiva, Minayo (2012, p. 300) afirma que “[...] métodos e instrumentos são caminhos mediadores para permitir ao pesquisador o aprofundamento de 
sua pergunta central e suas perguntas sucessivas, levantadas a partir do encontro com seu objeto empírico ou documental”.

A delimitação deste estudo compreende os 295 municípios pertencentes a Santa Catarina quanto ao acesso às linhas de crédito no âmbito do PRONAF por agricultores familiares. Como problemática de pesquisa, parte-se do seguinte questionamento: Como se deu a distribuição dos contratos e recursos financeiros do Programa Nacional de Fortalecimento da Agricultura Familiar (PRONAF) no estado de Santa Catarina no período compreendido entre 1996 e 2016 ?

Em termos metodológicos, este estudo apoiou-se principalmente na abordagem quantitativa. Inicialmente, realizou-se uma pesquisa bibliográfica sobre a temática da agricultura familiar, especialmente em trabalhos e estudos especializados em relação ao PRONAF. Em seguida, os dados quantitativos secundários em relação ao PRONAF foram acessados junto ao Banco Central do Brasil.

Os dados financeiros foram submetidos a deflação a partir do INPC, tendo como ano base o ano de 2016. A série histórica compreende o período de 1996 a 2016, ou seja, a totalidade dos dados temporais disponíveis quando da coleta dos dados. Por fim, realizouse a análise dos dados consultados sobre a distribuição do crédito PRONAF no estado de Santa Catarina, por meio da estatística descritiva.

\section{Distribuição do Crédito PRONAF em SANTa Catarina: ANálise de RESUltados}

Esta seção, além de detalhar os resultados da concessão de crédito ocorrida em Santa Catarina por meio das linhas de crédito de custeio e investimento, contempla a distribuição do crédito PRONAF no estado de Santa Catarina, o que evidencia traços de ineditismo, visto que este trabalho considera os dados de todo o conjunto da série histórica do programa (1996-2016). De maneira geral, o crédito destinado a investimentos são alocados a longo prazo, enquanto custeios são de curto prazo, mormente para o período de até 12 meses, uma vez que é destinado a culturas específicas, sendo refeitos anualmente para custear a produção.

Inicialmente, destaca-se que no período de 1996 a 2016, o estado de Santa Catarina efetivou o significativo número de 2.341 .832 contratos de crédito rural por meio do PRONAF, cuja maior parte foram destinados à finalidade de custeio, totalizando 1.886 .833 
contratos, equivalente a 80,6\% em relação ao montante total (Gráfico 2). Os contratos de investimentos somaram no período 454.969, o que representou 19,4\% do total de contratos. Os contratos de industrialização foram registrados apenas no ano de 2016 (ano de início dessa modalidade de crédito) e totalizaram somente 30 casos.

\section{Gráfico 2 - Número de contratos totais e de custeio efetivados via PRONAF por agricultores familiares} em Santa Catarina no período de 1996 a 2016

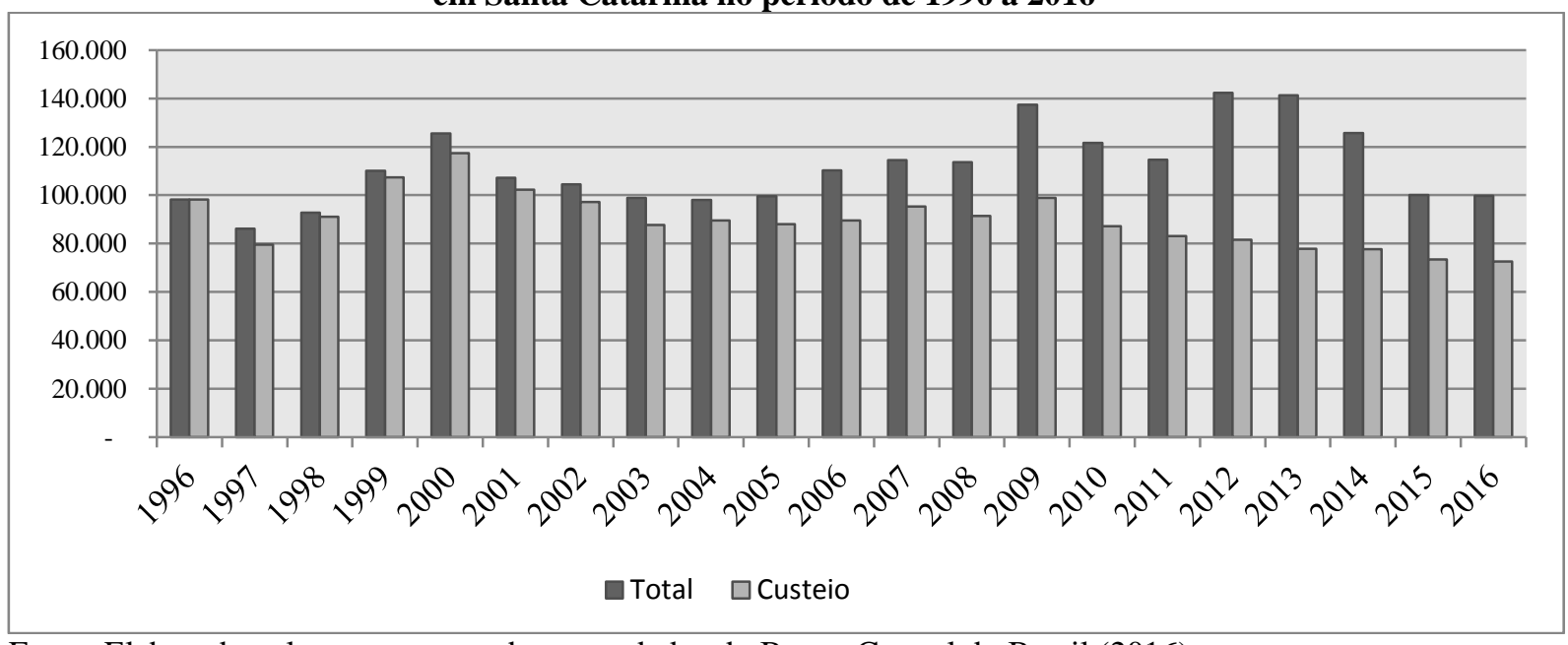

Fonte: Elaborado pelos autores com base em dados do Banco Central do Brasil (2016).

O alto percentual destinado para a finalidade de custeio assinala a dependência por parte dos agricultores no que tange à viabilização de suas atividades produtivas, o que Toledo (2009) classificou como "círculo vicioso" em torno do PRONAF. Em consequência, o aumento do número dos contratos para investimento no estado foi restrito no período entre 1996 e 2016, embora tenha ocorrido evolução desta finalidade a partir do ano de 2006. No referido ano, os contratos de investimento representaram 18,8\% em relação ao total, e dez anos depois, em 2016, registram-se $27,5 \%$ do total dos contratos somente para a linha de investimento. Essa evolução de certa forma impulsionou a ampliação da produção, estrutura e modernização das propriedades de agricultura familiar.

No que tange à distribuição entre as regiões do estado catarinense, a região Oeste é a que concentra o maior número de contratos, com percentual de $58 \%$ dos contratos do estado no período de 1996 a 2016. Essa concentração evidencia a predominância de um modo de agricultura que demonstra depender do crédito rural para o desenvolvimento das atividades produtivas, o que requer investigações que apontem em que medida o crédito se tornou um recurso indispensável à atividade. 
O Vale do Itajaí encontra-se como a segunda região com maior número de contratos efetivados, representado por 12\% (279.953). Na sequência, estão as regiões Sul, Norte, Serrana e Litoral, com 9,2\% (213.952), 8,8\% (206.359), 8\% (189.950) e 4\% (93.675) contratos por região respectivamente. Esta condição, assim como citado anteriormente, também pode estar associada às condições e estruturas da agricultura familiar em cada uma das regiões. Em futuros estudos com relação a essa temática, seria válido analisar o acesso ao crédito dos estabelecimentos rurais e/ou população rural de cada localidade por meio dos recentes dados disponíveis no censo agropecuário brasileiro.

No entanto, ao se realizar a comparação do número de contratos em 2016 com o número de contratos em 1996, é possível verificar a expansão de cada região em relação ao passado, efetivando outro cenário. Dessa forma, a região Serrana foi a que mais expandiu em relação ao número de contratos com índice ${ }^{5}$ de 4,92, seguida da Região Litorânea, que registrou um índice de 2,95. As regiões do Vale do Itajaí e Norte ficaram com índices de 1,67 e 1,61 respectivamente. E por fim as regiões Oeste, com 0,79, e Sul, com índice de 0,65 .

Esses índices regionais demonstram a expansão do PRONAF no estado no período em análise, e, como reflexo, atualmente essa política está presente nos 295 municípios catarinenses. Os dados revelam a redução em termos relativos da concentração dos contratos realizados na região Oeste, que passou de 70,6\% em 1996 para 55,2\% em 2016. No caso dessa região, essa diminuição do índice de participação nos contratos ocorre em consequência do aumento no número de contratos para as demais regiões em relação ao primeiro ano do PRONAF. Isso pode ser explicado pelo avanço no acesso à informação por parte dos agricultores familiares, que passam a conhecer a política e a utilizarem-na para o desenvolvimento das atividades produtivas. Os números de contratos por região e ano estão dispostos na Tabela 1 .

\footnotetext{
${ }^{5}$ Índice diz respeito à divisão do número de contratos 2016/1996.
} 
Revista Cadernos de Economia

Universidade Comunitária da Região de Chapecó - Unochapecó

Tabela 1 - Número de contratos totais realizados nas regiões de Santa Catarina via PRONAF no período de 1996 a 2016

\begin{tabular}{crrrrrrr}
\hline Ano/Região & Litoral & \multicolumn{1}{c}{ Oeste } & \multicolumn{1}{c}{ Norte } & Serrana & \multicolumn{1}{c}{ Sul } & Vale do Itajaí & \multicolumn{1}{c}{ Total } \\
\hline 1996 & 1.554 & 69.337 & 5.404 & 1.958 & 11.357 & 8.615 & 98.225 \\
1997 & 2.936 & 39.329 & 9.730 & 3.936 & 14.126 & 16.097 & 86.154 \\
1998 & 2.498 & 45.122 & 10.846 & 5.475 & 13.973 & 14.810 & 92.724 \\
1999 & 2.679 & 60.350 & 12.346 & 7.632 & 13.332 & 13.792 & 110.131 \\
2000 & 3.339 & 67.027 & 14.803 & 6.940 & 16.023 & 17.341 & 125.473 \\
2001 & 3.288 & 59.504 & 12.169 & 6.281 & 12.433 & 13.548 & 107.223 \\
2002 & 2.658 & 67.142 & 9.902 & 6.539 & 8.308 & 9.884 & 104.433 \\
2003 & 2.894 & 64.205 & 8.506 & 7.513 & 6.352 & 9.405 & 98.875 \\
2004 & 4.129 & 59.303 & 9.306 & 8.749 & 6.838 & 9.698 & 98.023 \\
2005 & 4.615 & 59.181 & 8.242 & 9.123 & 8.371 & 10.101 & 99.633 \\
2006 & 5.499 & 63.171 & 8.952 & 10.805 & 10.225 & 11.650 & 110.302 \\
2007 & 5.718 & 63.473 & 9.932 & 11.691 & 10.335 & 13.287 & 114.436 \\
2008 & 6.085 & 61.191 & 10.227 & 11.723 & 10.525 & 13.826 & 113.577 \\
2009 & 5.073 & 83.142 & 10.122 & 14.762 & 10.204 & 14.054 & 137.357 \\
2010 & 7.212 & 67.582 & 10.241 & 10.544 & 10.710 & 15.333 & 121.622 \\
2011 & 6.671 & 67.394 & 8.708 & 10.002 & 8.222 & 13.595 & 114.592 \\
2012 & 5.325 & 92.028 & 9.542 & 12.552 & 8.397 & 14.457 & 142.301 \\
2013 & 6.133 & 86.181 & 10.365 & 12.363 & 9.333 & 16.876 & 141.251 \\
2014 & 6.169 & 71.423 & 10.318 & 11.899 & 10.036 & 15.767 & 125.612 \\
2015 & 4.616 & 56.769 & 7.982 & 9.834 & 7.452 & 13.464 & 100.117 \\
2016 & 4.584 & 55.059 & 8.716 & 9.629 & 7.430 & 14.353 & 99.771 \\
\hline Total & 93.675 & 1.357 .913 & 206.359 & 189.950 & 213.982 & 279.953 & 2.341 .832 \\
\hline
\end{tabular}

Fonte: Elaborado pelos autores com base em dados do Banco Central do Brasil (2016).

Assim, como os contratos de crédito de custeio prevalecem no estado de Santa Catarina, nenhuma das regiões, de forma isolada, consegue romper de forma definitiva essa condição de dependência do Estado (média do estado no período: 81,9\%), as quais permanecem entre $80,6 \%$ e 86,9\%. Em termos absolutos, destaca-se a região Oeste, que já no ano de 2015 ultrapassou a marca de 1 milhão de contratos de custeio, finalizando o ano de 2016 com 1.074.987 contratos efetivados. Este elevado número de contratos está diretamente associado à finalidade do crédito de custeio de caráter imediato, ou seja, no curto prazo.

Em contrapartida, o acesso ao crédito de investimento ainda se apresenta de forma modesta (comparativamente ao crédito de custeio) em todas as regiões quando se observa o conjunto da série histórica. Entretanto, a partir de 2006, a linha de crédito apresenta crescimento em relação ao número de contratos totais do estado, chegando a seu ápice em 2014, quando atingiu 44,9\% do total de contratos. Tal evolução foi impulsionada pelo Programa Mais Alimentos, que permite financiar investimentos em infraestrutura 
produtiva, e que foi, majoritariamente, utilizado para a aquisição de maquinário agrícola, com destaque para a compra de tratores.

O acesso ao crédito de investimento para o agricultor familiar pode significar o fortalecimento de suas ações enquanto produtor, pois oportuniza condições para início e ampliação da produção e consequentemente também fortalece suas relações com os atores e o mercado, os quais poderão interferir na gestão e nos modos de produção da propriedade (RAMBO, 2014).

O montante de recursos financeiros contratados pelo estado de Santa Catarina, teve expressivo crescimento desde 1996 (ano de implantação do PRONAF). No primeiro ano de implantação, o estado contratou R \$ 495 milhões de reais, enquanto em 2016 o valor foi de $\mathrm{R} \$ 2,7$ bilhões de reais, valor que representa mais de cinco vezes o de 1996. O maior volume de recursos contratados foi no ano de 2014, quando o valor ultrapassou os $\mathrm{R} \$ 3,4$ bilhões de reais. Os resultados de 2015 e 2016 foram abaixo do nível de 2014, principalmente pelo registro de restrição hídrica (seca) no estado em 2014, e devido ao cenário econômico e político instável vivenciado no país naquele período.

O valor médio anual de aumento dos recursos no estado foi de $10,4 \%$, ocorrendo, a partir do ano de 2003, significativa expansão dos recursos contratados, a qual se estendeu até o ano de 2015, quando a queda em relação a 2014 foi de 26,5\%. Certamente a estiagem e o cenário econômico e político brasileiro da época podem ter contribuído para tal redução, mas uma investigação junto a agricultores rurais e demais atores relacionados à atividade seria custosa para procurar entender de que maneira isso se deu. O fato é que este declínio começou a ser registrado já desde o primeiro ano de implementação do PRONAF, uma vez que Santa Catarina se colocou entre os maiores estados contratantes, de modo que o crescimento e expansão do programa nas demais unidades da federação nos anos subsequentes levou o crescimento relativo desse estado a se dar de maneira proporcionalmente menor. 
Gráfico 3 - Evolução percentual do montante de recursos financeiros acessados no Brasil e em Santa Catarina via PRONAF no período de 1996 a 2016

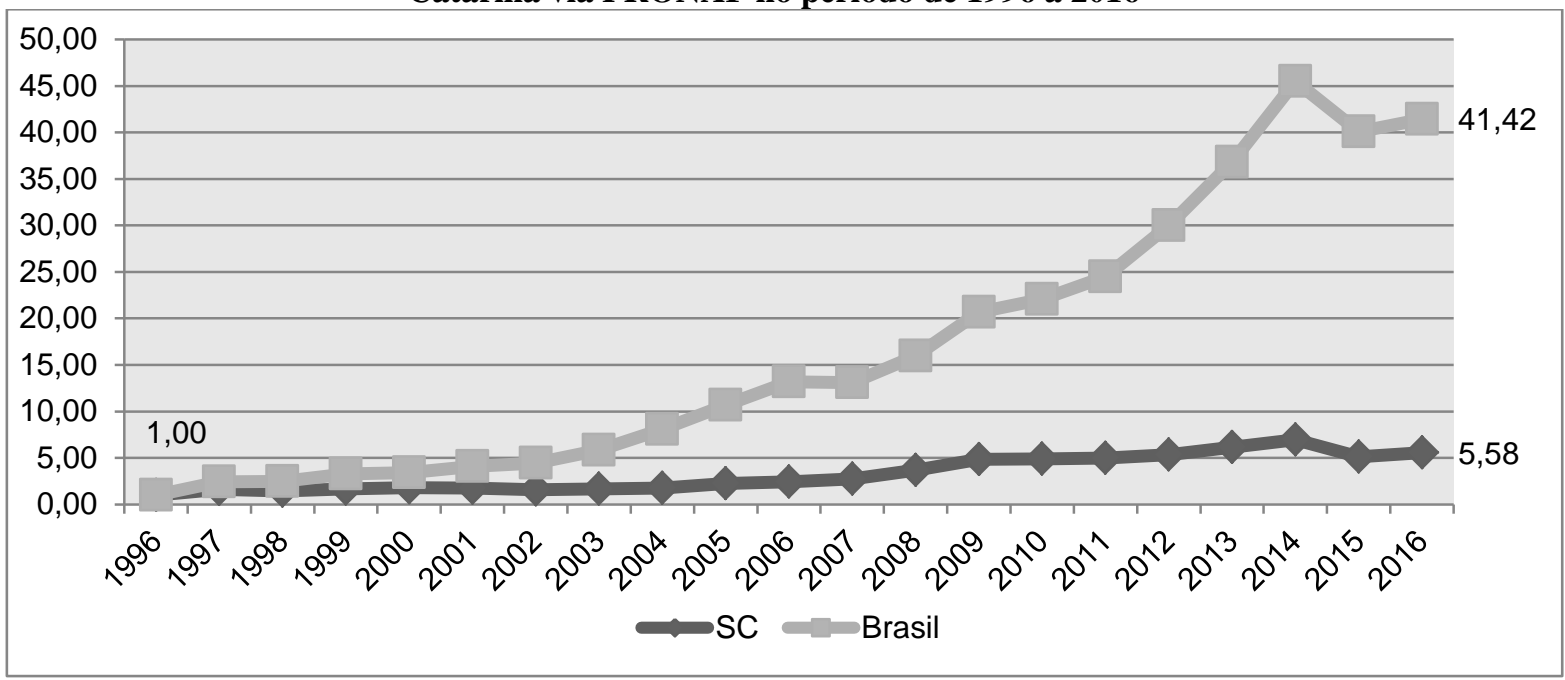

Fonte: Elaboração dos autores com base em dados do Banco Central do Brasil (2016).

- Índices de evolução obtidos a partir de 1996, sendo este ano Base = 1.

Em relação ao volume de recursos por finalidade no estado, assim como ocorre na perspectiva dos contratos, o crédito de custeio concentra a maior parcela dos recursos, sendo que, no período, essa linha de crédito representa em média 70,5\% do total dos financiamentos contratados no estado catarinense. Entretanto, o crédito de investimento no decorrer dos anos vem ganhando espaço, e nos últimos 10 anos (2007-2016) representou $42,9 \%$ do total. O crédito PRONAF para industrialização foi registrado apenas em 2016 e representou $4,3 \%$ em relação ao total do estado. 
Revista Cadernos de Economia

Universidade Comunitária da Região de Chapecó - Unochapecó

Tabela 2 - Montante de recursos financeiros acessados via PRONAF por finalidade contratados em Santa Catarina, no período de 1996 a 2016

\begin{tabular}{|c|c|c|c|c|c|c|}
\hline Ano & Valor Custeio & $\%$ & $\begin{array}{c}\text { Valor } \\
\text { Investimento }\end{array}$ & $\%$ & Valor Total & $\%$ \\
\hline 1996 & 495.112 .883 & 99,9 & 468.338 & 0,1 & 495.581 .221 & 100,0 \\
\hline 1997 & 597.686 .378 & 75,4 & 195.046 .782 & 24,6 & 792.733 .161 & 100,0 \\
\hline 1998 & 681.780 .137 & 94,1 & 42.868 .954 & 5,9 & 724.649 .091 & 100,0 \\
\hline 1999 & 767.841 .504 & 93,5 & 53.028 .964 & 6,5 & 820.870 .468 & 100,0 \\
\hline 2000 & 818.655 .783 & 91,8 & 73.374.337 & 8,2 & 892.030 .120 & 100,0 \\
\hline 2001 & 753.304 .243 & 85,5 & 127.974 .611 & 14,5 & 881.278 .853 & 100,0 \\
\hline 2002 & 612.103 .756 & 78,8 & 164.317 .198 & 21,2 & 776.420 .954 & 100,0 \\
\hline 2003 & 591.633 .296 & 71,7 & 233.658.759 & 28,3 & 825.292 .055 & 100,0 \\
\hline 2004 & 682.713 .645 & 78,4 & 188.492 .636 & 21,6 & 871.206 .280 & 100,0 \\
\hline 2005 & 814.943 .543 & 73,6 & 291.828 .554 & 26,4 & 1.106.772.097 & 100,0 \\
\hline 2006 & 866.738 .131 & 71,5 & 345.694 .359 & 28,5 & 1.212 .432 .490 & 100,0 \\
\hline 2007 & 1.015.308.529 & 74,3 & 350.756 .956 & 25,7 & 1.366 .065 .485 & 100,0 \\
\hline 2008 & 1.193.835.915 & 65,5 & 629.083 .749 & 34,5 & 1.822 .919 .664 & 100,0 \\
\hline 2009 & 1.266 .579 .981 & 52,5 & 1.147.302.875 & 47,5 & 2.413 .882 .856 & 100,0 \\
\hline 2010 & 1.286 .404 .830 & 52,8 & 1.147.809.261 & 47,2 & 2.434 .214 .091 & 100,0 \\
\hline 2011 & 1.309.376.258 & 53,0 & 1.161.304.939 & 47,0 & 2.470 .681 .197 & 100,0 \\
\hline 2012 & 1.423 .493 .841 & 53,6 & 1.234.064.399 & 46,4 & 2.657.558.241 & 100,0 \\
\hline 2013 & 1.505.115.390 & 49,3 & 1.550 .925 .777 & 50,7 & 3.056 .041 .168 & 100,0 \\
\hline 2014 & 1.569.396.841 & 45,5 & 1.879 .021 .458 & 54,5 & 3.448 .418 .299 & 100,0 \\
\hline 2015 & 1.578.774.329 & 62,3 & 955.477 .087 & 37,7 & 2.534 .251 .416 & 100,0 \\
\hline 2016 & 1.605.805.102 & 58,1 & 1.041.324.835 & 37,7 & 2.764 .938 .908 & 100,0 \\
\hline
\end{tabular}

Fonte: Elaboração do autor com base em dados do Banco Central do Brasil (2016).

- Valores deflacionados para o ano de 2016 pelo INPC.

Este incremento ocorrido na linha de crédito de investimento assume papel importante para a estrutura produtiva do segmento rural familiar, pois além de possibilitar a melhoria das condições de trabalho por meio da modernização dos equipamentos e dos métodos de trabalho, também tende a proporcionar condições para o aumento da produção e da produtividade.

Esta linha caracteriza-se por não limitar seus efeitos apenas no ano de contratação, mas também gerar efeitos ao longo dos anos posteriores à sua contratação, ou seja, o investimento se dilui em longo prazo. Contudo ressalta-se novamente que a evolução na linha de investimento, comparado com o restante do país, teve crescimento em menor grau.

$\mathrm{O}$ estado catarinense registrou crescimento de $27,2 \%$, enquanto o Brasil obteve crescimento de $67,8 \%$. Esse fato também se justifica pela expansão do programa nos demais estados da federação. O Gráfico 4 demonstra tal evolução em relação à linha de investimento no comparativo de Santa Catarina com o Brasil. 
Gráfico 4 - Comparativo da evolução do montante de recursos da linha PRONAF de investimento acessados no Brasil e em Santa Catarina via PRONAF no período de 1996 a 2016

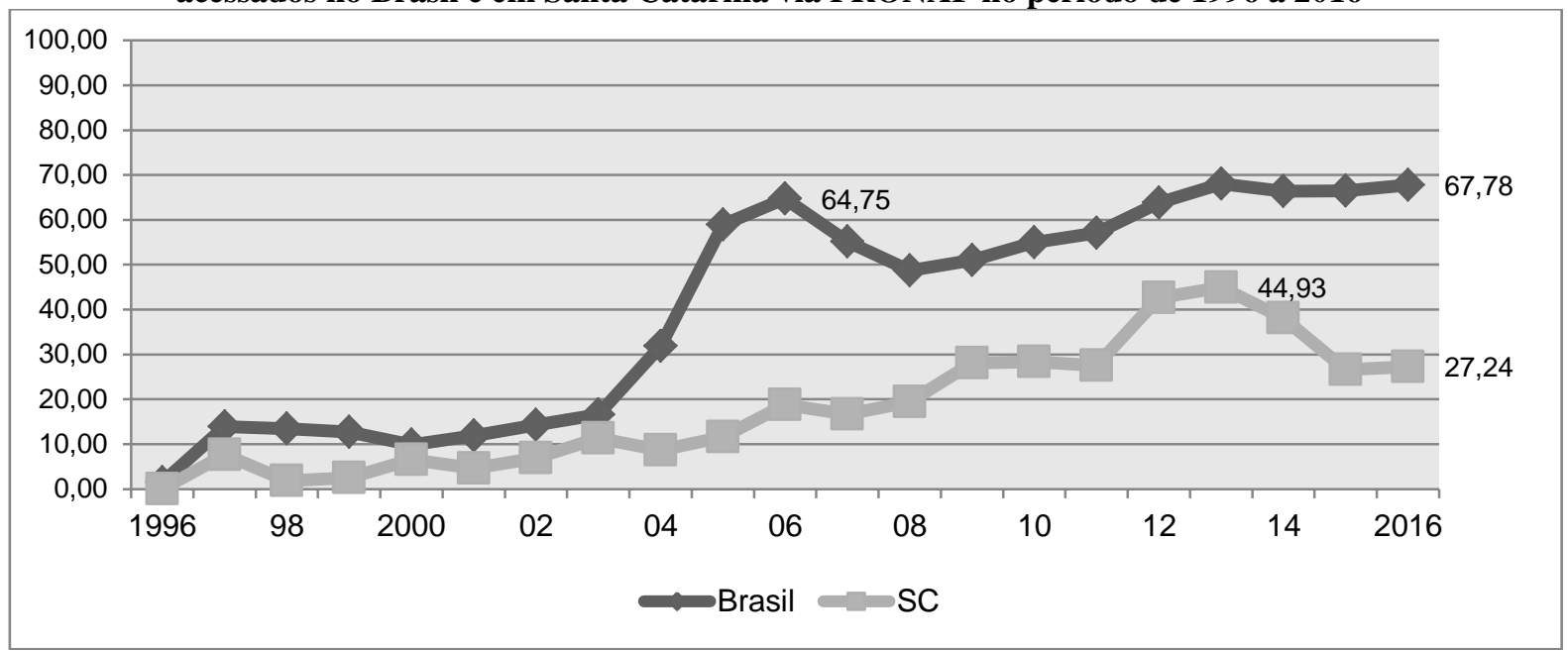

Fonte: Elaboração dos autores com base em dados do Banco Central do Brasil (2016).

- Índices de evolução obtidos a partir de 1996, sendo este ano Base $=1$.

O valor médio dos contratos teve um aumento significativo no período, pois como já destacado, a quantidade de contratos na comparação 1996/2016 manteve-se constante, enquanto o volume de recursos na mesma comparação teve um incremente superior a 5,5 vezes. O valor médio do crédito de custeio apresentou no período um crescimento linear, evidenciando de algum modo a necessidade cada vez maior de investimento para financiamento da produção por parte do agricultor. $\mathrm{O}$ valor médio passou de $\mathrm{R} \$ 5$ mil em 1996 para mais de R\$ 22 mil em 2016.

Gráfico 5 - Valor médio dos contratos de custeio e investimento acessados em Santa Catarina via PRONAF no período de 1996 a 2016

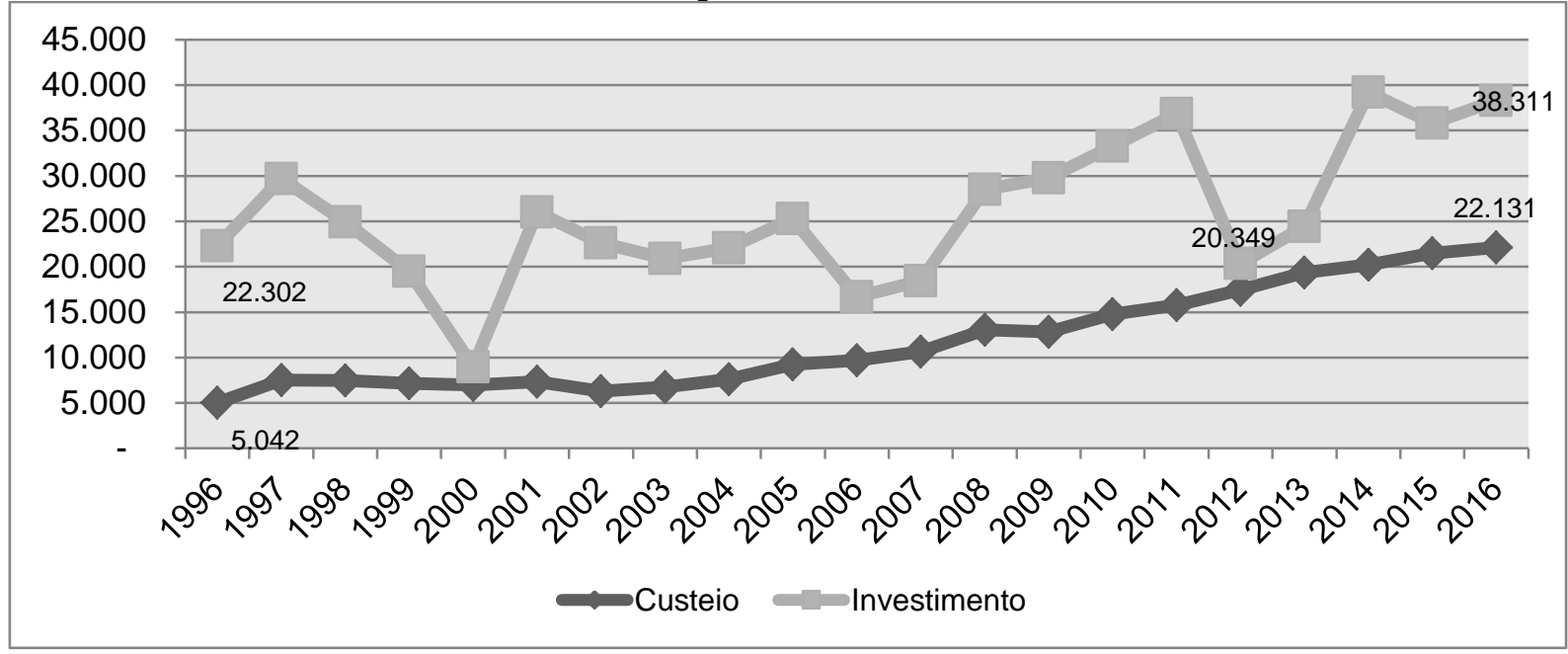

Fonte: Elaboração do autor com base em dados do Banco Central do Brasil (2016).

- Valores deflacionados para o ano de 2016 pelo INPC. 
O valor médio dos contratos de investimentos também teve crescimento, passando de R\$ 22 mil em 1996 para R\$ 38 mil em 2016, apesar de, em alguns anos, terem registrado queda no valor médio. Cabe ressaltar que no período 1996-2016 a variação do valor médio da linha de investimento foi pouco mais de $70 \%$, enquanto a variação do valor médio na linha de custeio foi de $439,0 \%$.

Em termos regionais, quanto ao volume de recursos financeiros contratados, a região Oeste é a responsável pela contratação do maior volume, que, ao longo da série histórica, representou 55,8\% do total. Em 2016, por exemplo, dos R 2,7 bilhões contratados pelo estado, $\mathrm{R} \$ 1,5$ bilhão foi pelos agricultores familiares da região Oeste, e quando observado todos os anos da série histórica, o valor contratado apenas no Oeste do estado ultrapassa os $\mathrm{R} \$ 19$ bilhões de reais.

Tabela 3 - Montante de recursos financeiros contratados por região em Santa Catarina, via PRONAF no período de 1996 a 2016

\begin{tabular}{|c|c|c|c|c|c|c|c|}
\hline Ano & Litoral & Oeste & Norte & Serrana & Sul & Vale do Itajaí & Total SC \\
\hline 1996 & 9.329 .736 & 312.681 .823 & 28.178 .168 & 15.163 .344 & 84.849 .412 & 45.378 .738 & 495.581 .221 \\
\hline 1997 & 21.813 .116 & 389.641 .785 & 74.564 .339 & 39.269 .995 & 126.494 .741 & 140.949 .185 & 792.733 .161 \\
\hline 1998 & 23.207.049 & 301.610 .139 & 78.335 .272 & 50.983 .178 & 137.625 .944 & 132.887 .509 & 724.649 .091 \\
\hline 1999 & 27.272 .834 & 368.965 .314 & 105.538 .904 & 60.818 .436 & 132.467 .858 & 125.807 .122 & 820.870 .468 \\
\hline 2000 & 33.651 .300 & 386.385 .202 & 118.301 .902 & 60.496 .580 & 145.412 .519 & 147.782 .618 & 892.030 .120 \\
\hline 2001 & 35.115 .019 & 415.582 .463 & 107.171.393 & 52.252 .472 & 134.339 .204 & 136.818 .302 & 881.278 .853 \\
\hline 2002 & 29.154 .576 & 456.884 .012 & 72.109 .654 & 47.732 .181 & 76.835 .598 & 93.704 .933 & 776.420 .954 \\
\hline 2003 & 32.803 .792 & 499.093 .486 & 72.665 .644 & 59.239 .707 & 60.826 .629 & 100.662 .797 & 825.292 .055 \\
\hline 2004 & 45.711 .347 & 479.782 .984 & 86.105 .316 & 65.912 .727 & 79.649 .809 & 114.044 .097 & 871.206 .280 \\
\hline 2005 & 53.678 .024 & 627.819 .628 & 87.252 .957 & 80.518 .298 & 124.211 .291 & 133.291 .900 & 1.106 .772 .097 \\
\hline 2006 & 63.876 .342 & 630.364 .691 & 95.521 .818 & 101.822 .314 & 152.611 .942 & 168.235 .383 & 1.212 .432 .490 \\
\hline 2007 & 70.242 .349 & 721.858 .939 & 116.399 .447 & 123.370 .610 & 142.718 .063 & 191.476 .077 & 1.366 .065 .485 \\
\hline 2008 & 87.851 .250 & 992.449 .206 & 158.013 .260 & 159.047 .288 & 176.576 .408 & 248.982.252 & 1.822 .919 .664 \\
\hline 2009 & 91.633 .998 & 1.411 .899 .776 & 188.549 .881 & 208.150 .645 & 202.949 .287 & 310.699 .269 & 2.413 .882 .856 \\
\hline 2010 & 141.725 .885 & 1.335 .865 .968 & 197.995 .771 & 174.111 .543 & 237.282 .870 & 347.232 .054 & 2.434.214.091 \\
\hline 2011 & 130.630 .123 & 1.495 .366 .499 & 180.235 .894 & 193.944 .471 & 167.403 .093 & 303.101 .116 & 2.470 .681 .197 \\
\hline 2012 & 101.153 .648 & 1.616 .833 .573 & 183.378.082 & 220.610 .743 & 206.931 .816 & 328.650 .378 & 2.657 .558 .241 \\
\hline 2013 & 127.115 .226 & 1.809 .451 .948 & 226.106 .263 & 253.373.754 & 242.659 .091 & 397.334 .886 & 3.056 .041 .168 \\
\hline 2014 & 152.939 .982 & 1.928 .830 .617 & 294.627 .327 & 295.139 .847 & 335.882 .111 & 440.998 .415 & 3.448 .418 .299 \\
\hline 2015 & 99.275 .999 & 1.451 .461 .127 & 186.284 .763 & 225.697 .904 & 221.292 .986 & 350.238 .637 & 2.534 .251 .416 \\
\hline 2016 & 103.781 .844 & 1.537.398.571 & 218.961 .648 & 243.313.912 & 246.667 .894 & 414.815 .040 & 2.764 .938 .908 \\
\hline Total & 1.481 .963 .439 & 19.170 .227 .750 & 2.876 .297 .701 & 2.730 .969 .949 & 3.435 .688 .567 & 4.673 .090 .709 & 34.368 .238 .115 \\
\hline
\end{tabular}

Fonte: Elaboração do autor com base em dados do Banco Central do Brasil (2016).

- Valores deflacionados para o ano de 2016 pelo INPC.

A região do Vale do Itajaí se posiciona na sequência em termos de volume contratado, registrando no período a quantia de $\mathrm{R} \$ 4,6$ bilhões, o que significou 13,6\% em relação ao total. A região Sul é a terceira região que mais contratou no período (19962016), com um volume de R \$ 3,4 bilhões, correspondendo a 10\% do total. Os volumes de recursos contratados pelas demais regiões estão contidos na Tabela 3. 
No que se refere à distribuição entre os municípios, dividimos os 295 em 4 grupos pelo volume de recursos contratados no período 1996-2016, o primeiro com os 10 municípios que mais contrataram PRONAF, o segundo com os 30 municípios que mais acessaram recursos pelo programa, o terceiro grupo com os 30 municípios que obtiveram a menor contratação, e o quarto, com os 235 municípios que ficaram no intervalo entre os 30 primeiros e os 30 últimos.

Os 10 municípios que mais acessaram crédito PRONAF totalizaram no período aproximadamente $\mathrm{R} \$ 5,6$ bilhões de reais, o que representou 16,3\% do total. Dentre estes, oito municípios pertencem à região Oeste, um à região do Litoral, e outro, à região do Vale do Itajaí. Os 30 municípios que mais acessaram recursos do programa juntos totalizaram 35,5\% do total, representando R \$ 12,2 bilhões de reais no período 1996-2016.

Tabela 4 - Relação dos 10 municípios que com maior volume de contratação de recursos financeiros contratados, via PRONAF no período de 1996 a 2016

\begin{tabular}{c|l|c|c|c|c}
\hline Ordem & Município & $\begin{array}{c}\text { Valor. Custeio } \\
(\mathbf{R} \mathbf{)}\end{array}$ & $\begin{array}{c}\text { Valor. Invest. } \\
(\mathbf{R} \mathbf{)}\end{array}$ & $\begin{array}{c}\text { Valor. Indust. } \\
(\mathbf{R} \mathbf{)})\end{array}$ & $\begin{array}{r}\text { Valor Total } \\
(\mathbf{R} \mathbf{)}\end{array}$ \\
\hline 1 & CHAPECÓ & 515.326 .007 & 198.133 .026 & 39.408 .000 & 752.867 .033 \\
2 & CONCÓRDIA & 462.230 .515 & 233.766 .513 & 8.085 .084 & 704.082 .111 \\
3 & PALMITOS & 392.280 .282 & 291.050 .615 & 5.000 .000 & 688.330 .898 \\
4 & PINHALZINHO & 241.289 .477 & 377.577 .772 & 10.000 .000 & 628.867 .249 \\
5 & ITUPORANGA & 366.432 .803 & 159.709 .676 & - & 526.142 .479 \\
6 & GUARACIABA & 372.380 .241 & 151.370 .043 & - & 523.750 .284 \\
7 & ALFREDO WAGNER & 298.428 .329 & 148.516 .723 & - & 446.945 .052 \\
8 & CUNHA PORÃ & 267.920 .365 & 171.322 .799 & 5.300 .000 & 444.543 .165 \\
9 & VIDEIRA & 316.774 .576 & 116.839 .902 & 8.300 .541 & 441.915 .019 \\
10 & ITAPIRANGA & 253.939 .817 & 187.710 .653 & - & 441.650 .470 \\
\hline
\end{tabular}

Fonte: Elaboração do autor com base em dados do Banco Central do Brasil (2016).

- Valores deflacionados para o ano de 2016 pelo INPC.

O grupo formado pelos 30 municípios que menos acessaram o crédito PRONAF representa apenas $0,7 \%$ do total, sendo este grupo formado exclusivamente por municípios litorâneos de Norte a Sul do estado, os quais não possuem sua base econômica centrada na agricultura. E o grupo central, ou seja, formado pelos municípios que não ocupam as extremidades, representou $63,8 \%$ do total de crédito contratado no estado.

Estas estatísticas demonstram disparidades entre municípios e também entre as regiões do estado, sendo que essa condição se associa a estrutura, potencial e características 
da agricultura familiar de cada localidade e/ou região. Entretanto, o PRONAF, enquanto política pública, possui a atribuição de apoio e fortalecimento aos produtores rurais.

\section{CONSIDERAÇÕES FINAIS}

No estado de Santa Catarina, a predominância de propriedades de agricultura familiar evidencia a relevância da participação dessa atividade no volume total da produção agropecuária do estado. Neste cenário, o PRONAF, enquanto política pública de concessão de crédito rural, assume importante papel enquanto instrumento propulsor de desenvolvimento das atividades socioprodutivas da agricultura familiar na medida em que viabiliza a produção. As linhas de crédito do programa possibilitam ao conjunto de agricultores familiares financiarem o custeio da produção, bem como os investimentos para ampliação e modernização de estruturas produtivas.

A partir da implantação do PRONAF, Santa Catarina se posiciona como um dos principais contratantes dessa linha de crédito no país. Se constata um crescimento tanto em volume de recursos como na quantidade de contratos acessados ao amparo do PRONAF por agricultores familiares catarinenses. Esse resultado pode ser explicado tanto pelo aumento no custo de produção, como também pela constituição de um processo de dependência dessa política pública. Mesmo assim, o programa representa uma forma de política pública que tem viabilizado o desenvolvimento de diferentes atividades produtivas por meio do custeio ou investimento. No entanto, o PRONAF representa uma dentre tantas outras políticas públicas que tem fortalecido a agricultura familiar em busca de autonomia e reprodução social.

No período de 1996-2016, o estado de Santa Catarina apresentou crescimento significativo no que se refere ao volume de recursos, registrando crescimento superior a $550 \%$, enquanto o número de contratos, apesar de também ter obtido crescimento no decorrer do período, manteve-se com quantidades semelhantes ao do ano base 1996 ao final da série histórica. $\mathrm{O}$ crédito de custeio apresentou crescimento linear, passando o valor médio do contrato de R \$ 5 mil em 1996 para R\$ 22 mil no ano de 2016. Já o crédito para investimento, que no início do programa no estado foi praticamente nulo, com o passar dos anos foi tendo seus valores incrementados, especialmente a partir do ano de 2008 com a 
criação da linha de crédito Mais Alimentos. A linha de crédito para industrialização foi registrada apenas no ano de 2016.

A região Oeste concentra a maior parte dos contratos e recursos, uma vez que os percentuais acessados somente por esta região ultrapassam $50 \%$ do total do estado. Dentre os 10 municípios que mais contrataram recursos no período 1996-2016, 8 pertencem à região Oeste. Nas demais regiões, nenhuma se destaca sobre a outra, variando seus percentuais de participação até 13\%. Esta distribuição regional está diretamente ligada à vocação econômica e estrutura da agricultura familiar de cada região.

Por fim, cabe ressaltar que o PRONAF é uma política pública com importante papel no financiamento de atividades produtivas da agricultura familiar. Sua relevância é observada por meio dos dados apresentados nesse estudo, reforçando a contribuição da distribuição desse recurso para as dinâmicas econômicas locais e para a reprodução da agricultura familiar, permanecendo como principal forma produtiva no meio rural desse estado.

Com base nos resultados alcançados por meio dessa análise, é possível apontar a necessidade de compreender os motivos que orientam a renovação no número de contratos e o aumento do volume de recursos necessários para a atividade. Terá alguma relação com endividamento, aumento nos custos de produção ou mudança de atividade produtiva? Questões essas que merecem investigação junto a agricultores familiares que tenham acessado o crédito rural nos últimos anos.

\section{REFERÊNCIAS}

AQUINO, Joacir Rufino de; SCHNEIDER, Sergio. O PRONAF e o desenvolvimento rural brasileiro: avanços, contradições e desafios para o futuro. In: GRISA, Catia; SCHNEIDER, Sergio (Orgs.). Políticas Públicas de Desenvolvimento Rural no Brasil. Porto Alegre: UFRGS, 2015. p. 53-81.

BIANCHINI, Valter. Vinte anos do PRONAF, 1995 - 2015: avanços e desafios. Brasília: SAF/MDA, 2015.

BRAMBILlA, M.A.; MICHELLON, E. Focalização do Pronaf na região Sul do Brasil. Revista de Economia, Curitiba, v. 40, n. 72, p. 115-133, 2019.

BRASIL. Banco Central do Brasil. Anuário Estatístico do Crédito Rural, 1996-2016. 2016. Disponível em: http://www.bcb.gov.br/ . Acesso em: 01 fev. 2020. 
BRASIL. Decreto n. 1.946, de 28 de junho de 1996. Cria o Programa Nacional de Fortalecimento da Agricultura Familiar (PRONAF). Diário Oficial [da] República Federativa do Brasil, Brasília, DF, de 1 set. 1996b.

BRASIL. Lei 11.326, de 24 de julho de 2006. Estabelece as diretrizes para a formulação da Política Nacional da Agricultura Familiar e Empreendimentos Familiares Rurais. Diário Oficial [da] República Federativa do Brasil, Brasília, DF, 2006.

BRASIL. Ministério da Agricultura e do Abastecimento. PRONAF - Programa Nacional de Fortalecimento da Agricultura Familiar. Brasília, maio de 1996.

CAMPOS, Índio. Os colonos do Rio Uruguai: relações entre pequena Produção e Agroindústria no Oeste Catarinense. 1987. 370 f. Dissertação (Mestrado em Economia) Universidade Federal da Paraíba, Campina Grande, 1987.

CARNEIRO, Maria José. Política pública e agricultura familiar: uma leitura do PRONAF. Estudos Sociedade e Agricultura, Rio de Janeiro, n. 8, p. 70-82, abr. 1997.

FACHINELLO, Arlei; SANTOS FILHO, Jonas Irineu dos. Agricultura e agroindústria catarinenses: panorama, impasses e perspectivas do sistema agropecuário. In: MATTEI, Lauro, LINS, Hoyêdo Nunes. A socioeconomia catarinense: cenários e perspectivas no início do século XXI. Chapecó: Argos, 2010. p. 159-196.

FAO - Organização das Nações Unidas para a Alimentação e a Agricultura; INCRA Instituto Nacional de Colonização e Reforma Agrária do Brasil. Diretrizes de política agrária e desenvolvimento sustentável. Resumo do Relatório Final do Projeto UTF/BRA/036, segunda versão. Brasília: FAO/INCRA, 1994.

GOULARTI FILHO, Alcides. Formação econômica de Santa Catarina: uma tentativa de síntese. In: MATTEI, Lauro, LINS, Hoyêdo Nunes. A socioeconomia catarinense: cenários e perspectivas no início do século XXI. Chapecó: Argos, 2010. p. 29-62.

GRISA, Catia; SCHNEIDER, Sergio. Três gerações de políticas públicas para agricultura familiar e formas de interação entre sociedade e Estado no Brasil. In: GRISA, Catia; SCHNEIDER, Sergio (Orgs.). Políticas Públicas de Desenvolvimento Rural no Brasil. Porto Alegre: UFRGS, 2015. p. 19-50.

GRISA, Catia; WESZ JUNIOR, Valdemar João; BUCHWEITZ; Vitor Duarte. Revisitando o PRONAF: velhos questionamentos, novas interpretações. RESR, Piracicaba-SP, Vol. 52, No 02, p. 323-346, Abr/Jun 2014.

GUANZIROLI, Carlos Enrique. PRONAF dez anos depois: resultados e perspectivas para o desenvolvimento rural. Revista de Economia Rural, Rio de Janeiro, v. 45, n. 2, p. 301328, abr./jun. 2007.

KÖCHE, José Carlos. Fundamentos de metodologia científica: teoria da ciência e iniciação à pesquisa. 32. ed. atual. Petrópolis: Vozes, 2013. 
MATTEI, Lauro. O debate sobre a reforma agrária no contexto do Brasil rural atual. Política \& Sociedade. Florianópolis, Vol. 15 - Edição Especial - 2016.

MATTEI, Lauro. Políticas públicas de apoio à agricultura familiar: o caso recente do PRONAF no brasil. Raízes, v.35, n.1, jan-jun /2015.

MATTEI, Lauro. PRONAF 10 anos: mapa da produção acadêmica. Brasília: MDA, 2006. (NEAD Estudos).

MINAYO, Maria Cecilia de Souza. O desafio do conhecimento: pesquisa qualitativa em saúde. São Paulo: HUCITEC, 2012.

MONTEIRO, A.P.; LEMOS, J. J.S. Desigualdades na distribuição dos recursos do Pronaf entre as regiões brasileiras. Revista Política Agrícola, Brasília, v. 28, n. 1, Jan./Fev./Mar. 2019.

RAMBO, Fabiano Lazarotto. O Programa PRONAF Mais Alimentos: um estudo de caso da microregião de Pinhalzinho (SC). 2014. 106f. Dissertação (Mestrado Profissional em Políticas Sociais e Dinâmicas Regionais). Universidade Comunitária da Região de Chapecó, Programa de Pós-Graduação em Políticas Sociais e Dinâmicas Regionais, Chapecó, 2014.

RENK, Arlene Anélia. Sociodicéia às Avessas. Chapecó: Grifos, 2000.

SEYFERTH, Giralda. Campesinato e o Estado no Brasil. RAMBO, v. 17, n. 2, p. 395-417, 2011.

SPANEVELlO, Rosani Marisa; MATTE, Alessandra; BOSCARDIN, Mariele. Crédito rural na perspectiva das mulheres trabalhadoras rurais da agricultura familiar: uma análise do Programa Nacional de Fortalecimento da Agricultura Familiar (PRONAF). Polis Revista Latinoamericana, v. 44, 2016.

TOLEDO, Elizário Noé Boeira; SCHNEIDER, Sergio. O PRONAF em Salvador das Missões: Contradições de uma política de crédito. 2009. 186f. Dissertação (Mestrado em Desenvolvimento Rural) - Universidade Federal do Rio Grande do Sul, Porto Alegre, 2009.

VICENZI, Renilda. Mito e história na colonização do oeste catarinense. Chapecó: Argos, 2008.

WANDERLEY, Maria de Nazareth Baudel. "Franja Periférica", "Pobres do Campo", "Camponeses": dilemas da inclusão social dos pequenos agricultores familiares. In: DELGADO, Guilherme Costa; BERGAMASCO, Sonia Maria Pessoa Pereira. Agricultura Familiar Brasileira: Desafios e Perspectivas de Futuro. Brasília: Ministério do Desenvolvimento Agrário, 2017. p. 66-83.

WERLANG, Alceu Antonio. Disputas e ocupação do espaço no oeste catarinense: a atuação da Companhia Territorial Sul Brasil. Chapecó: Argos, 2006. 